\title{
Erupção Liquenóide: Secundária ao Uso de Adalimumabe?
}

\section{Lichenoid Eruption: Secondary to Adalimumab?}

\author{
Maria Cristina Bezzan Goldschmidt ${ }^{(1)}$, Mariana Colombini Zaniboni ${ }^{(2)}$, José Roberto Provenza ${ }^{(3)}$, Lúcia Arruda ${ }^{(4)}$
}

\section{RESUMO}

O adalimumabe é um anticorpo recombinante monoclonal IgGl, completamente humano, que se liga especificamente ao fator de necrose tumoral alfa (TNF- $\alpha$ ) e neutraliza sua atividade. Relatamos aqui um caso de erupção liquenóide secundária ao uso de adalimumabe em uma paciente com artrite reumatóide. O quadro melhorou após a suspensão do adalimumabe, com recidiva à reintrodução do medicamento e nova melhora após a suspensão definitiva deste. Embora a paciente estivesse recebendo, concomitantemente ao adalimumabe, metotrexate, corticosteróides e outras drogas, não houve suspensão ou modificação das medicações, exceto o adalimumabe durante todo o período. A ocorrência de erupção liquenóide com o uso do adalimumabe é um evento não esperado, uma vez que, na imunopatologia do líquen plano, o papel do TNF- $\alpha$ parece ser o de propagador da doença. Desse modo, esperaria-se que drogas anti-TNF- $\alpha$ pudessem ser usadas no tratamento do líquen plano e não que atuassem como indutoras desta condição.

Palavras-chave: líquen plano, fator de necrose tumoral alfa, anticorpos monoclonais, erupção por droga, artrite reumatóide.

\section{INTRODUÇÃO}

O adalimumabe é um anticorpo monoclonal humano recombinante anti-fator de necrose tumoral alfa $(\mathrm{TNF}-\alpha)^{(1)}$.

É usado no tratamento de artrite reumatóide (AR), artrite psoriática, psoríase, espondilite anquilosante e doença de $\operatorname{Crohn}^{(2,3)}$.

Efeitos colaterais cutâneos são menos observados com o uso do adalimumabe em relação às outras medicações com efeitos anti-TNF- $\alpha$ (etanercepte e infliximabe) ${ }^{(4)}$.

Relatamos um caso de erupção liquenóide após o uso de adalimumabe, com coincidência temporal entre o uso da droga e o aparecimento das lesões e melhora com a sua suspensão.

\begin{abstract}
Adalimumab is a recombinant, fully human IgGI monoclonal antibody that binds specifically to human TNF- $\alpha$ and neutralizes the activity of this cytokine. We report herein the case of a lichenoid eruption with the use of adalimumab in a patient with rheumatoid arthritis. The eruption improved after interruption of adalimumab, with recurrence at the reintroduction and improvement again with definitive suspension. Although this patient was receiving concomitant adalimumab with methotrexate, corticosteroids and other drugs, these medications except the adalimumab were not discontinued or modified at any moment during the period. The occurrence of lichenoid eruption with adalimumab is a not expected event since the function of the TNF- $\alpha$ in the immunopathology of lichen planus seems to be as a propagator of disease. This way, we would expect that drugs with anti-TNF- $\alpha$ effect would not act as inductors of lichen planus but could be used in its treatment.
\end{abstract}

Keywords: lichenoid eruptions, antibodies, monoclonal, tumor necrosis factor-alpha, drug eruptions, arthritis, rheumatoid.

\section{RELATO DE CASO}

Mulher de 68 anos, com AR há cinco anos, estava em uso de metotrexate (12,5 mg/semana), ácido fólico, prednisona (10 mg/dia), difosfato de cloroquina $(250 \mathrm{mg} / \mathrm{dia})$, diclofenaco (uso irregular), amitriptilina, captopril, hidroclorotiazida, raloxifeno, carbonato de cálcio e vitamina D há mais de dois anos.

Em virtude da manutenção do quadro inflamatório articular intenso, com limitações importantes das atividades diárias, em setembro de 2004, o adalimumabe foi associado às medicações anteriores, na dose de $40 \mathrm{mg}$ subcutâneo, a cada 15 dias. Houve melhora do quadro articular, mas, após a quinta injeção, a paciente iniciou lesões cutâneas

Recebido em 10/4/2007. Aprovado, após revisão em 17/12/2007. Declaramos a inexistência de conflitos de interesse.

Serviço de Dermatologia do Hospital e Maternidade Celso Pierro da Pontifícia Universidade Católica de Campinas (Puccamp)

1. Médica residente de Dermatologia do Serviço de Dermatologia do Hospital e Maternidade Celso Pierro da Puccamp.

2. Médica assistente do Serviço de Dermatologia do Hospital e Maternidade Celso Pierro da Puccamp.

3. Chefe do Serviço de Reumatologia do Hospital e Maternidade Celso Pierro da Puccamp.

4. Chefe do Serviço de Dermatologia do Hospital e Maternidade Celso Pierro da Puccamp.

Endereço para correspondência: Maria Cristina Bezzan Goldschmidt, Rua Sebastião Vieira de Andrade, 30, Estância Recreativa San Fernando, 13278-110, Valinhos, SP, e-mail: crisbezzan@yahoo.com.br 
pruriginosas que consistiam de placas eritêmato-violáceas com halo eritematoso e estrias de Wickham, simétricas, nos membros inferiores (Figura 1).

O diagnóstico clínico e anatomopatológico foi de erupção liquenóide secundária ao adalimumabe, e a medicação foi suspensa com melhora significativa do quadro cutâneo (Figura 2).

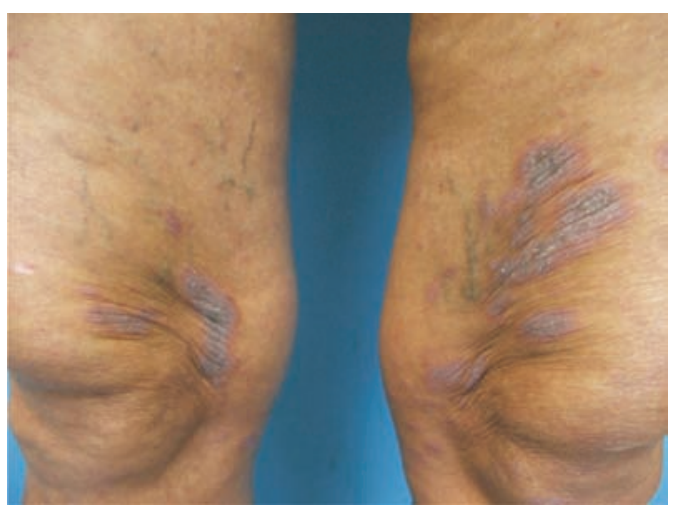

Figura 1 - Placas violáceas com halo eritematoso.

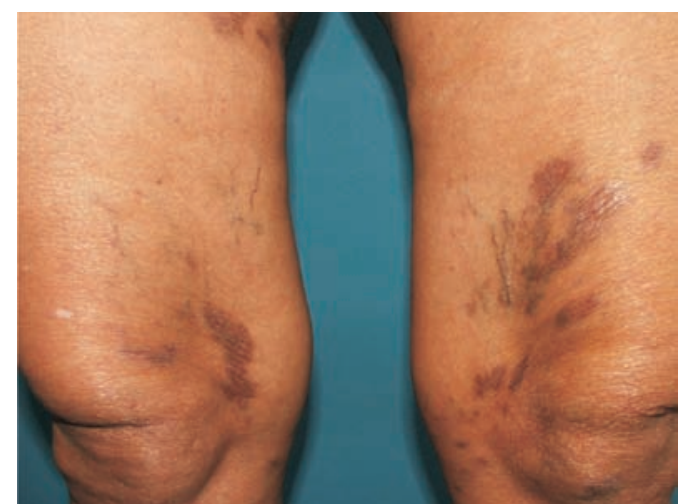

Figura 2 - Placas acastanhadas, denotando lesões em regressão.

O adalimumabe voltou a ser utilizado em abril de 2005 , por causa da piora da AR; foram utilizadas três injeções e houve recidiva das lesões cutâneas. A medicação foi novamente suspensa e a paciente apresentou melhora das lesões, principalmente do quadro inflamatório cutâneo. Não houve modificação no uso das demais drogas, que foram mantidas com as mesmas dosagens.

Desde então a paciente não apresentou recidiva das lesões.

\section{DISCUSSÃO}

$\mathrm{O}$ adalimumabe é um anticorpo monoclonal humano recombinante $\mathrm{IgGl}$ anti-fator de necrose tumoral alfa (TNF- $\alpha$ ), que se liga especificamente ao TNF- $\alpha$ solúvel e presente na membrana celular e inibe sua interação com os receptores p75 e p55. O adalimumabe também liga células que expressam TNF, in vitro, na presença de complemento $^{(1,2)}$. Foi aprovado para uso na AR refratária, na dose de $40 \mathrm{mg}$ em injeção subcutânea a cada duas semanas, podendo ser usado isoladamente ou associado ao metotrexate ou outras drogas anti-reumáticas modificadoras de doença ${ }^{(5)}$.

Os efeitos colaterais mais importantes associados às drogas inibidoras de TNF- $\alpha$ (adalimumabe, infliximabe e etanercepte) são infecção, linfoma, insuficiência cardíaca congestiva, síndrome lúpus-símile, exacerbação de alveolite fibrosante, indução de auto-anticorpos e reações no local da injeção ${ }^{(6-10)}$. Em relação às reações adversas específicas do adalimumabe, além das anteriormente descritas, foram relatados síndrome nefrótica, indução de doença pulmonar intersticial, citopenias, elevação de transaminases e reações alérgicas; estas últimas são raras, fato esperado, uma vez que a estrutura e a função do adalimumabe são indistinguíveis das de uma IgGl humana, mas pode ocorrer imunogenicidade à droga, com o desenvolvimento de anticorpos (acredita-se que os locais com potencial imunogênico se desenvolvam após a ligação do adalimumabe ao TNF- $\alpha$ ) $(4,11,12)$. Até o momento não existe evidência suficiente de que o adalimumabe aumente a ocorrência de tuberculose ou de infecções fúngicas ${ }^{(2)}$. A associação entre o uso do adalimumabe e a ocorrência de doença desmielinizante ainda está sob investigação ${ }^{(13)}$.

Reações cutâneas adversas parecem ser menos comuns com o adalimumabe em relação ao etanercepte e ao infliximabe, visto que reação no local da injeção ocorre em $1,5 \%$ a $11 \%$ e exantemas não-específicos em $4,5 \%$ a $10,1 \%$ dos pacientes ${ }^{(4)}$. Outros efeitos colaterais cutâneos são celulite, erisipela, herpes-zóster ${ }^{(6)}$, urticária e erupção fixa à droga, principalmente nos primeiros meses de tratamento ${ }^{(8)}$.

Em pacientes portadores de AR que usam adalimumabe, já foram descritas as seguintes alterações cutâneas: celulite eosinofílica (síndrome de Wells), reação eritema multiforme-símile, vasculite leucocitoclástica, vasculite cutânea com granulomas eosinofílicos, psoríase e erupção psoriasiforme, erupção papulosa linfomatóide-símile, rosácea, eczema não-específico e lesões neoplásicas ${ }^{(8,11,14-16)}$. 
No caso descrito, o diagnóstico de líquen plano/ erupção liquenóide foi confirmado por meio de exame histológico e a sua relação com o adalimumabe observada pela melhora clínica após suspensão da droga e recidiva à reintrodução.

Devemos ainda ressaltar que a paciente já utilizava previamente drogas sabidamente causadoras de erupção liquenóide ${ }^{(17)}$ (captopril, difosfato de cloroquina, hidroclorotiazida), assim como prednisona, droga usada no tratamento de quadros graves de erupção liquenóide ${ }^{(17)}$, porquanto todas as medicações foram mantidas com a mesma posologia, durante todo o período, não havendo, portanto, relação que justificasse o quadro clínico.

\section{REFERÊNCIAS}

1. Baker DE: Adalimumab: human recombinant immunoglobulin Gl anti-tumor necrosis factor monoclonal antibody. Rev Gastroenterol Disord 4: 196-210, 2004.

2. Olsen NJ, Stein CM: New drugs for rheumatoid arthritis. N Engl J Med 350: 2167-79, 2004.

3. Chew AL, Bennett A, Smith CH, Baker J, Kirkham B: Successful treatment of severe psoriasis and psoriatic arthritis with adalimumab. Br J Dermatol 151: 492-6, 2004.

4. Weinblatt ME, Keystone EC, Furst DE, et al.: Adalimumab, a fully human anti-tumor necrosis factor $\alpha$ monoclonal antibody, for the treatment of rheumatoid arthritis in patients taking concomitant methotrexate: the ARMADA trial. Arthritis Rheum 45: 35-45, 2003.

5. Navarro-Sarabia F, Ariza-Ariza R, Hernàndez-Cruz B, Villanueva I: Adalimumab for treating rheumatoid arthritis. J Rheumatol 33: 1075-8, 2006.

6. Scheinfeld N: A comprehensive review and evaluation of side effects of the tumor necrosis factor alpha blockers etanercept, infliximab and adalimumab. J Dermatolog Treat 15: 280-94, 2004.

7. Devos SA, van de Bossche N, De Vos M, Naeyaert JM : Adverse skin reaction to anti-TNF-alpha monoclonal antibody therapy. Dermatology 206: 388-90, 2003.

8. Scheinfeld N: Adalimumab: a review of side effects. Expert Opin Drugs Saf 4: 637-1, 2005.

9. Zeltser R, Valle L, Tanck C, et al.: Clinical, histological, and immunophenotypic characteristics of injection site reactions associated with etanercept: a recombinant tumor necrosis factor $\alpha$ receptor: Fc fusion protein. Arch Dermatol 137: 893-9, 2001.

10. Allanore Y, Devos-François G, Caramella C, et al.: Fatal exacerbation of fibrosing alveolitis associated with systemic sclerosis in a patient treated with adalimumab. Ann Rheum Dis 65: 834-5, 2006.
Encontramos na literatura o relato de um paciente de 71 anos, portador de AR, que apresentou erupção liquenóide sete meses após iniciar o uso de adalimumabe, com melhora do quadro após suspensão da medicação ${ }^{(15)}$. Além do uso concomitante de naproxeno (droga que pode induzir erupção liquenóide) ${ }^{(17)}$, não houve reintrodução do adalimumabe, não sendo possível, portanto, estabelecer ao certo uma relação entre o adalimumabe e o quadro cutâneo.

Apesar de não existir elucidação completa da imunopatologia do líquen plano, parece que o TNF- $\alpha$ possui papel importante na propagação da doença ${ }^{(18-20)}$. Assim, esperarse-ia que um inibidor do TNF- $\alpha$ não estivesse associado com a ocorrência de erupção liquenóide.

11. Beuthien W, Mellinghoff HU, von Kempis J: Skin reaction to adalimumab. Arthritis Rheum 50: 1690-2, 2004.

12. Schoe A, van der Laan-Baalbergen NE, Huizinga TW, Breedveld FC, van Laar JM: Pulmonary fibrosis in a patient with rheumatoid arthritis treated with adalimumab. Arthritis Rheum 55: 157-9, 2006.

13. Berthelot CN, George SJ, Hsu S: Distal lower extremity paresthesia and foot drop developing during adalimumab therapy. J Am Acad Dermatol 53: S260-2, 2005.

14. Orpin SD, Majmudar VB, Soon C, Azam NA, Salim A: Adalimumab causing vasculitis. Br J Dermatol 154: 998-9, 2006.

15. Flendrie M, Vissers WHPM, Creemers MCW, et al.: Dermatological conditions during TNF- $\alpha$-blocking therapy in patients with rheumatoid arthritis: a prospective study. Arthritis Res Therapy 7: 666-76, 2005.

16. Boura P, Sarantopoulos A, Lefaki I, Skendros P, Papadopoulos P: Eosinophilic cellulitis (Wells' syndrome) as a cutaneous reaction to the administration of adalimumab. Ann Rheum Dis 65: 839$40,2006$.

17. Burns T, Breathnach S, Cox N, Griffiths C: Rook's textbook of dermatology. 7.ed. Blackwell Publishing Company, 2004.23.

18. Thongprasom K, Dhanuthai K, Sarideechaigul W, Chaiyarit P, Chaimusig M: Expression of TNF- $\alpha$ in oral lichen planus treated with fluocinolone acetonide $0,1 \%$. J Oral Pathol Med 35: 161-6, 2006.

19. Gordon KB, Bonish BK, Patel T, Leonardi CL, Nickoloff BJ: The tumor necrosis factor- $\alpha$ inhibitor adalimumab rapidly reverses the decrease in epidermal Langerhans cell density in psoriatic plaques. Br J Dermatol 153: 945-53, 2005.

20. Erdem MT, Gulec AI, Kizilyunc A, Yildirim A, Atasoy M: Increased serum levels of tumor necrosis factor alpha in lichen planus. Dermatology 207: 367-70, 2003. 